\author{
С. К. Егорова \\ (Санкт-Петербургский государственный университет)
}

\title{
ГОРАЦИЙ И ВИНОДЕЛИЕ
}

Гораций упоминает виноделие как одно из своих занятий, однако нигде expressis verbis не говорит о собственном винограднике. Среди упоминаний, не дающих четких сведений о растениях в его в Сабинском поместье, выделяется место, которое кажется аргументом в пользу произрастания других растений (перец и ладан, Epist. 1, 14, 23 f.), однако это topos adynaton, который невозможно использовать в аргументации. Между тем первое значение использованного здесь существительного angulus позволяет сделать предположить, что ввиду горного ландшафта только часть участка была пригодна для выращивания винограда, что сделало виноделие не источником дохода, а лишь хобби великого поэта, отмечавшего так годы памятных для себя событий.

Ключевые слова: античное виноделие; Гораций; Carm. 1, 20; diota; Epist. 1, 14, 23.

S. K. Egorova

(St. Petersburg State University)

\section{Horace as vigneron}

Horace mentions his own home-made wine at least once (Carm. 1, 20, 1-4; one may interpret Carm. 1, 9, 7-8 and 3, 8, 9-12 in the same way), but there is no exact information of his own vineyard.

After a brief overview of passages where Horace mentions his Sabine farm and its agricultural aspect (Serm. 2, 7, 118; Serm. 2, 6, 1-4; Epist. 1, 16, 110; 1, 8, 3-6), I reconsider Epist. 1, 14, 23 f.: though the poet mentions the production of plants of completely different kind rather than vine ( $« \ldots$ et quod / angulus iste feret piper et tus ocius uva»), these words are an evident topos adynaton and cannot be used as an argument in the question under consideration. Meanwhile the noun angulus, though probably denoting the whole estate, still can be understood literally, as a section of the territory, apparently the only one suitable for a vineyard. Then wine-making was not the main source of income for Horace, but a hobby which permitted him to mark the years of memorable events.

Keywords: Horace, ancient wine-making; Carm. 1, 20; diota; Epist. 1, $14,23$.

Для этой статьи я выбрала частный и не имеющий почти никакого исторического значения вопрос - был ли у Горация свой виноградник. При этом следует сразу оговорить, что 
археологические данные о вилле в Личенце ${ }^{1}$, которая - возможно - принадлежала Горацию, я привлекала лишь в случае общих сведений - так, например, в этой местности практиковалось и до сих пор практикуется выращивание винограда (с преобладанием белых сортов, однако возможно выращивание и красных ${ }^{2}$ ), тогда как основным материалом исследования являются литературные источники.

\section{Упоминание вина собственного производства}

О том, что Гораций сам заливал вино в амфоры и закрывал (lino, levi/livi, litum, linere) их при помощи глины (или смолы, см. ниже), читаем в оде 1,20 :

Vile potabis modicis Sabinum cantharis, Graeca quod ego ipse testa conditum levi, datus in theatro cum tibi plausus, care Maecenas eques, $<\ldots>^{3}$

Поскольку наличие у Горация имения в Сабинских горах не вызывает сомнений, из этого упоминания можно заключить, что речь идет о вине, произведенном там же. Важным представляется то обстоятельство, что это событие не являлось обычным - поэт подчеркивает, что сделало это сам (ego ipse) и по достопамятному поводу — овации Меценату, впервые появившемуся в театре после тяжелой болезни.

Два других места, возможно, также говорят о производстве своего вина:

Carm. 1, 9, 7-8:

Dissolve frigus ligna super foco large reponens atque benignius deprome quadrimum Sabina, o Thaliarche, merum diota ${ }^{4}$.

\footnotetext{
${ }^{1}$ Подробнее см.: Schmidt 1997 и https://www.licenzaturismo.it/localitavilla-di-orazio Гдата обращения 19.03.20201.

${ }^{2}$ Frischer, Brown 2017: 51: «... resembled Burgundy of the middling sort».

3 Далее в стихах 9-12 Гораций противопоставляет скромное сабинское прославленным сортам, которые Меценат пьет обычно: Caecubum et prelo domitam Caleno / tu bibes uvam; mea nec Falernae / temperant vites neque Formiani / pocula colles.

${ }^{4} \mathrm{C}$ вариантами Sabino ... diota в двух рукописях ( $\delta$, Ох.), см. подробнеe: Egorova 2020: in print.
} 
Хотя здесь упоминается просто «четырехлетнее сабинское», по моему мнению, обозначение сосуда как diota может указывать на «домашнее» происхождение вина. Заинтересовавшись этим редким словом (оно встречается только здесь, а в греческом является узкоспециальным прилагательным), я предполагаю, что речь идет о том же, что обозначено в Carm. 1, 20 как Graeca testa - согласно догадке Нисбета и Хаббард речь идет о специфическом способе консервации сосуда при помощи соли, который использовался для продления срока хранения вина, химически к этому не предрасположенного ${ }^{5}$ : «a Greek jar was impregnated with salt which would act as a preservative ... Graeca like levi emphasizes the care taken to preserve a wine of great sentimental value but relatively little staying power» ${ }^{6}$.

Другой пассаж дает нам сходные сведения: в Carm. 3, 8 Гораций рассказывает, что ежегодно празднует день чудесного спасения от упавшего дерева (ст. 7-8: prope funeratus / arboris ictu):

Hic dies anno redeunte festus corticem adstrictum pice dimovebit amphorae fumum bibere institutae consule Tullo ${ }^{7}<\ldots>$

Как и в случае с овацией Меценату, речь идет о праздновании памятного события и упоминаются дополнительные подробности консервации сосуда - смола (ріх), которой закреплялась пробка (cortex) амфоры ${ }^{8}$, из чего можно заключить, что речь идет не о покупном, а о вине собственного производства.

${ }^{5}$ Гален в пересказе Афинея (Deipn. 1, 27 b) сообщает, что сабинское вино созревает в течение 7 лет, но хранится не больше 15 лет. Подробнее о соотношении этих данных с лирикой Горация см.: Cairns 2012: 225.

${ }^{6}$ Nisbet-Hubbard 1970: 247-248. Существуют и другие интерпретации этого словосочетания - так Пейдж и многие другие комментаторы не видят ничего странного во вторичном использовании амфоры (см., например, Colum. 12, 28, 4), возможно, для придания вину дополнительного аромата (Page 1962: 182), а Коммаджер (Commager 1962: 326) предлагает понимать всю ситуацию метафорически: речь идет о вливании латинских песен в форму греческой поэзии.

${ }^{7}$ L. Volcatius Tullus, cos. 33 г. до н. э. (считается, что его отец был консулом слишком «рано» - в 66 г. до н. э., хотя Гораций упоминает и вино 65 г. в Carm. 3, 21: O nata mecum consule Manlio... testa).

${ }^{8}$ Вопрос о практике окуривания вина в данной статье рассматриваться не будет. Принято считать, что окуривание дымом применялось для состаривания вина, однако в данном случае этого не требовалось: по стихам 17-24 ода датируется 25 г. до н. э., что делает вино 8-летним (a 


\section{Описание Сабинского поместья}

Однако сделать вывод о наличии виноградника эти эпизоды не позволяют - сырье могло доставляться и с других участков по соседству.

К сожалению, столь же неопределенное впечатление создают и другие упоминания хозяйственной стороны жизни в Сабинском поместье ${ }^{9}$ ) - прежде всего оно было для поэта местом философского уединения в противовес суетной жизни в Риме (см., например, Serm. 2, 6, особенно ст. 60-76).

О небольшом размере поместья ${ }^{10}$ можно судить как по самому характеру гористой местности, так и по угрозе Даву отправить его в Сабины девятым рабом (Serm. 2, 7, 118). ${ }^{11} \mathrm{~B}$ Послании к управляющему упоминаются 5 очагов, обычно сопоставляемые с количеством арендаторов (Epist. 1, 14, 2).

Тем не менее, в уже упомянутой сатире (Serm. 2, 6, 1-4) дается описание поместья, которое все же превзошло ожидания поэта:

Hoc erat in votis: modus agri ${ }^{12}$ non ita magnus,

hortus ubi et tecto vicinus iugis aquae fons

et paulum silvae super his foret. auctius atque

di melius fecere.

Наиболее подробно о растительности в своем поместье - и то переводя разговор на тему курортов - Гораций пишет в 16-м Послании:

в современной терминологии 9-летним), т. е. и так достаточно зрелым (см. выше прим. 5).

Ager Sabinus, Sabini, Lucretilis, rus etc., перечень упоминаний приводит, например, Дуров 2015: 88. Можно предположить, что для обозначения загородного поместья Гораций часто использует и название ближайшего города - Тибура (Carm. 1, 7; 2, 6, 2, 6, 5 et al.). Однако возможно, что у Горация были и поместье, и дом на территории современного Тиволи: в Carm. 3, 4, 23 Sabini и Tibur названы отдельно, в том же ключе можно трактовать и сообщение Светония: «vixit plurimum in secessu ruris sui Sabini aut Tiburtini, domusque eius ostenditur circa Tiburni luculum».

10 Классификация поместий применительно к нашему случаю приводится, например, Шмидтом: Schmidt 1997: 21-23.

${ }_{11}$ Сходным образом можно понять противопоставление довольного немногим мудреца с владельцами огромных поместий: ... desiderantem quod satis est neque / ... sollicitat $<\ldots\rangle$ / non verberatae grandine vineae / fundusque mendax... (Carm. 3, 1, 25-3).

${ }^{12} \mathrm{~K}$ сожалению, это слово имеет слишком общее значение, не дающее представления о сельхозкультурах. 
Ne perconteris, fundus meus, optime Quinti, arvo pascat erum an bacis opulentet olivae, pomisne et pratis an amicta vitibus ulmo, scribetur tibi forma loquaciter et situs agri. Continui montes, ni dissocientur opaca valle $\quad<\ldots>$ Quid, si rubicunda benigni corna vepres et pruna ferant, si quercus et ilex multa fruge pecus, multa dominum iuvet umbra?

Из перечня растений скорее садово-паркового типа (кизил ${ }^{13}$, слива, дуб, остролист) можно заключить, что поместье если и приносит плоды, то не того ценного сельскохозяйственного свойства, о котором справляется Квинтий в начале Послания, иными словами, виноград там не выращивается ${ }^{14}$.

В другом Послании Гораций упоминает виноградные лозы и оливы, но в фигуре отрицания (Epist. 1, 8, 3-6):

Si quaeret quid agam, dic multa et pulchra minantem vivere nec recte nec suaviter, haud quia grando contunderit vitis oleamque momorderit aestus, nec quia longinquis armentum aegrotet in agris; sed quia mente minus validus <...>

Этот переход к этическому рассуждению снова не дает нам однозначных результатов: мы можем как предположить, что виноградник есть, но не побит градом, так и заключить, что основу скромного хозяйства составляет не виноделие (см. сходное противопоставление в Carm. 3, 1, 25-32, прим. 11).

Последним аргументом в этом разделе могло бы стать упоминание венка из виноградных листьев в обиходном контексте - что означало бы наличие их под рукой. Однако и тут - по данным, собранным М. С. Касьян (Касьян 2014: 416), - нет уверенности: такой венок (pampineus, a, um) упоминается, но как атрибут Диониса (Carm. 3, 25, 20; 4, 7, 33).

\section{Topos adynaton: Hor. Epist. 1, 14, 23}

Перейдем к упоминанию винограда, которое представляется в нашем вопросе наиболее ценным. В 14-м Послании, адре-

\footnotetext{
${ }^{13}$ В Древнем Риме были известны плодовые сорта, дававшие ягоды, пригодные для засолки подобно оливкам.

${ }^{14}$ Возможно, речь шла скорее о животноводстве - скот упоминается и в Serm. 2, 6, 14, хотя, возможно, в составе шутки: Maia nate, ... pingue pecus domino facias et cetera praeter / ingenium.
} 
сованном управляющему, Гораций предвидит сетования последнего:

... et quod

angulus iste feret piper et tus ocius uva,

nec vicina subest vinum praebere taberna

quae possit tibi, ...

Р. Майер (Mayer 2012: 209) понимает это место так: поле скорее принесет перец и ладан, нежели виноград, т. е. совсем его не принесет ${ }^{15}$. При этом исследователи ${ }^{16}$ сходятся в том, что серьезно воспринимать вероятность произрастания именно этих восточных культур ${ }^{17}$ не приходится, это упоминание - явный topos adynaton. Но тогда эта фигура речи не обязательно исключает произрастание винограда вообще. В моем понимании она скорее призвана подчеркнуть сложность выращивания винограда - скорее $^{18}$ вырастишь что-то невозможное, чем добьешься обыденного результата (и большая часть хлопот ложится на плечи управляющего, которому владелец высказывает оформленную таким образом благодарность).

Важным словом здесь представляется существительное angulus. Хотя его можно трактовать и как обозначение всего имения (со значением уединенности - "remote seclusion" Mayer 2012: 209, как в Carm. 1, 6, 14, где речь идет о Тибуре), мне представляется возможным видеть здесь указание в прямом смысле - на угол участка, о котором поэт и собеседник говорят то и дело ${ }^{19}$.

${ }^{15}$ Следующий за этим недостаток имения (nec vicina subest vinum praebere taberna / quae possit tibi), на первый взгляд, подкрепляет этот аргумент: не только имение не дает вина, так еще и таверны нет «в шаговой доступности». Однако здесь речь идет совсем о другом управляющий может пить вино (и вообще развлекаться —далее упоминаются музыка и танцы) в таверне, а не из хозяйских погребов, о наличии или отсутствии которых эта подробность снова ничего не говорит.

${ }^{16}$ Schmidt 1997: 159; Mayer 2012: 209: «these spices come from the East».

${ }^{17}$ Создается впечатление, что Гораций не совсем отчетливо представляет себе производства ладана, считая его плодами растения, тогда как это продукт из смолы Ладанного дерева (Босвеллии священной) или Ливанского кедра.

${ }^{18}$ ocius следует понимать не во временном значении, а - как и русское «скорее» - 'more easily', OLD s. v. ociter 4.

${ }^{19} O L D$ s. v. iste 2 : in echoing a word... 'that which you mention' 
Можно предположить, что в условиях гористой местности (continui montes, Epist. 1, 16, 5, см. выше) только небольшая часть принадлежавшей поэту земли имела минимальные характеристики, необходимые для виноградника ${ }^{20}$. В таком случае при небольших масштабах всего имения производство вина не имело экономического значения, но это не мешало владельцу гордиться своим собственным сабинским - как говорится, сделанным своими руками.

\section{Литература}

Cairns, F. 2012: The Power of Implication: Horace's Invitation to Maecenas (Ode I. 20). Romantic Lyric. Collected Papers on Catullus and Horace. Berlin; Boston: De Gruyter, 213-243.

Commager, S. 1962: The Odes of Horace: A Critical Study. New Haven; London: Yale University Press.

Durov, V. S. 2015: Unacquainted Horace. St. Petersburg.

Дуров, В. С. 2015: Незнакомый Горачий. СПб: Филологический ф-т СПбГУ.

Egorova, S. 2020: Forgotten Variants. Hyperboreus 26 (2020). In print.

Fricher, B. D., Brown, I. G. 2017: Allan Ramsay and the Search for Horace's Villa. New York: Routledge.

Kasyan, M. S. 2014: [What kind of wreath will crown the poet? (Horatii Od. I, 38)]. Indoevropeiskoe yazvkoznanie $i$ klassicheskava filologiya [Indo-European linguistics and classical philology] 14, 409-418.

Касьян, М. С. 2014: Какой венок увенчает поэта? (Horatii Od. I, 38). Индоевропейское языкознание и классическая филология $14,409-418$.

Mayer, R. 2012: Horace: Odes. Book I. Cambridge: Cambridge University Press.

Nisbet, R. G. M., Hubbard, M. 1970: A Commentary on Horace: Odes. Book I. Oxford: Clarendon.

Page, T. E. 1962: Q. Horati Flacci Carminum Libri IV, Epodon Liber (ed., comm.). London, New York: Macmillan.

Schmidt, E. A. 1997: Sabinum. Heidelberg: Universitätsverlag C. Winter.

\footnotetext{
${ }^{20}$ Пособия для начинающих рекомендуют устраивать виноградник на участках с пологими южными и юго-западными склонами, крутизна которых не должна превышать $10-12^{\circ}$. Из тех же источников мне стало известно, что соседство с узкой долиной (ср. Epist. 1, 16, 5-6) делает виноградник уязвимым для заморозков и мучнистой росы.
} 